number, and displacement of the inferior thyroid artery. None of these are specific to the condition.

Venous sampling from catheterization of the thyroid venous bed usually shows raised levels of calcitonin and parathyroid hormone on both sides of the neck, higher values being obtained than in the peripheral circulation. Sampling in this way does not appear to have much value in diagnosis, which is more easily achieved by peripheral sampling for calcitonin with or without calcium infusion. ${ }^{5}$ The characteristic radiological features of the familial syndrome can be of help in the diagnosis of this thyroid tumour and complement the more specific histological and hormonal abnormalities.

\footnotetext{
1 Pearson, K. D., Wells, S. A., and Keiser, H. R., Radiology, 1973, 107, 249. 2 Wallace, S., Hill, C. S., Paulus, D. D., Ibanez, M. L., and Clark, R. L., Radiologic Clinics of North America, 1970, 8, 463.

Radiologic Clinics of North America, 1970, 8, 463.
Sandler, M., Karim, S. M. M., and Williams, E. D., Lancet, 1968, 2, 1053.

4 Schimke, R. N., Hartmann, W. H., Prout, T. E., and Rimoin, D. L., New England fournal of Medicine, 1968, 279, 1 .

5 Jackson, C. E., Tashjian, A. H., and Block, M. A., Annals of Internal Medicine, 1973, 78, 845 .
}

\section{Abdominal Cysts}

Intra-abdominal cysts lying behind the peritoneal cavity or between its leaves-in the mesentery and the omentum-are unusual, rarely diagnosed with accuracy before operation, and interesting. They can be grouped together conveniently from both clinical and pathological aspects. R. M. HandfieldJones" defined retroperitoneal cysts as "those cysts lying in the retroperitoneal fatty tissues which have no connection with any adult anatomical structure save by areolar tissue." This definition applies well enough to the others. A cystic mass in the retroperitoneal area is most likely to have origin from the kidney or the pancreas, but these do not fall within the definition of a true retroperitoneal cyst.

Usually the cysts are single, unilocular or multilocular, with contents that range from clear and straw-coloured through chylous fluid to thick, cheesy material. They may or may not have an epithelial lining. There may be evidence of recent or past intracyst haemorrhage. Calcification may take place and malignant change is rare. Other complications include rupture, infection, torsion, and pressure on adjacent structures.

Oliver Beahrs and his colleagues ${ }^{2} \mathbf{3}$ at the Mayo Clinic have provided a convenient aetiological classification for these swellings into four main groups. The first are embryonic and developmental cysts. These include enteric cysts, usually situated in the mesentery of the lower ileum. They are unilocular, contain yellowish-brown mucinous fluid, and represent sequestration from the intestine. Urogenital cysts represent Wolffian remnants and are commoner in females than males. Also in this group are lymphatic cysts, arising from embryonic defects in lymph tissues, and finally dermoids, which contain skin derivatives such as sebaceous material, hair, and even teeth. The second group are traumatic in origin and result from organization of a haematoma. The third group are neoplastic. The growths may be benign or malignant and include lymphangiomata. The fourth group are infective and degenerative cysts of mycotic, parasitic, or tuberculous origin.
The parasitic cysts are hydatids, and the tuberculous cysts result from caseating tuberculous mesenteric adenitis.

Clinical features of this condition have recently been well reviewed by A. R. Walker and T. C. Puthnam, ${ }^{4}$ of the University of Rochester School of Medicine, New York, who collected 33 examples of operatively confirmed omental, mesenteric, and retroperitoneal cysts, an incidence of one case per 35,400 hospital admissions. Six were in males, 27 in females; the age ranged from the newborn to 76 years. Thirteen of the cysts were omental, 18 mesenteric, and 2 retroperitoneal. Three females with mesenteric cysts were incompletely detailed, but of the 30 fully documented patients 5 presented as emergencies (1 with haemorrhage, 1 with torsion, 2 ruptured, and 1 with obstruction), 13 underwent elective operation for the mass, and 12 were incidental findings at other operations. A small cyst is likely to be asymptomatic and impalpable and therefore discovered only incidentally at laparotomy. In the 12 such cases in this series only three were larger than $4 \mathrm{~cm}$ in diameter and the smallest of the clinically significant cysts was $6 \mathrm{~cm}$ in diameter. An accurate preoperative diagnosis is also unlikely in the acute cases, in which abdominal rigidity may prevent palpation of the mass. Walker and Putnam suggest that more accurate preoperative diagnosis might be possible in the symtomatic but non-acute cysts. The masses are usually described as being smooth, round, mobile, and non-tender. Retroperitoneal cysts are likely to be relatively fixed, omental cysts are mobile in all directions, and mesenteric cysts tend to be more mobile in the transverse than in the cephalocaudal plane. Cystic masses which appear to be tethered to the pelvis are more likely to originate from the uterus, ovaries, or bladder.

Often the patient complains of pain, which may be due to stretching of peritoneum on the root of the mesentery. Subacute obstruction may result from extrinsic pressure on the intestine. $X$-ray studies are of considerable importance. A plain film of the abdomen often shows a soft-tissue mass, perhaps with calcification. A lateral view of the abdomen may show that the mass lies anterior to the intestines, which suggests the possibility of an omental cyst. A barium meal and follow-through and a barium enema $x$-ray examination may show bowel displacement and rule out primary disease of the alimentary tract. Similarly, intravenous pyelography excludes a renal lesion, though it may show obstruction or displacement of ureters or compression of the bladder. Selective superior mesenteric angiography has been carried out in one case of mesenteric cyst but was normal. ${ }^{5}$ In one further example it was of some diagnostic assistance. ${ }^{6}$

Walker and Putnam conclude that there are no diagnostic clinical characteristics which permit an accurate preoperative diagnosis in these lesions. However, such cysts should be suspected in any patient with a mobile abdominal mass, with or without chronic pain, in whom plain and contrast $x$-ray studies of the abdomen show the mass to be extrinsic to the alimentary and urinary tracts.

\footnotetext{
1 Handfield-Jones, R. M., British Fournal of Surgery, 1924, 12, 119. Beahrs, O. H., and Dockerty, M. B., Surgical Clinics of North America, $1950,30,1073$.

${ }^{8}$ Beahrs, O. H., Judd, E. S., and Dockerty, M. B., Surgical Clinics of North America, 1950, 31, 1081.

Walker, A. R., and Putnam, T. C., Annals of Surgery, 1973, 178, 13. 5 Oh, C., Danese, C. A., and Dreiling, D. A., Archives of Surgery, 1967, 94, 790 .

- Potter, B. M., and McSweeney, W. J., Radiology, 1973, 106, 285.
} 